\title{
Strategies to manage patients with dental anxiety and dental phobia: literature review
}

This article was published in the following Dove Press journal:

Clinical, Cosmetic and Investigational Dentistry

10 March 2016

Number of times this article has been viewed

\section{Deva Priya Appukuttan}

Department of Periodontics, Sri Ramakrishna Mission Dental College and Hospital, Chennai, India
Correspondence: Deva Priya Appukuttan Department of Periodontics, Sri Ramakrishna Mission Dental College and Hospital, Bharathi Salai, Ramapuram, Chennai, Tamil Nadu 600 089, India $\mathrm{Tel}+9$ | 9840 |97 I2।

Email devapriyamds@gmail.com
Abstract: Dental anxiety and phobia result in avoidance of dental care. It is a frequently encountered problem in dental offices. Formulating acceptable evidence-based therapies for such patients is essential, or else they can be a considerable source of stress for the dentist. These patients need to be identified at the earliest opportunity and their concerns addressed. The initial interaction between the dentist and the patient can reveal the presence of anxiety, fear, and phobia. In such situations, subjective evaluation by interviews and self-reporting on fear and anxiety scales and objective assessment of blood pressure, pulse rate, pulse oximetry, finger temperature, and galvanic skin response can greatly enhance the diagnosis and enable categorization of these individuals as mildly, moderately, or highly anxious or dental phobics. Broadly, dental anxiety can be managed by psychotherapeutic interventions, pharmacological interventions, or a combination of both, depending on the level of dental anxiety, patient characteristics, and clinical situations. Psychotherapeutic interventions are either behaviorally or cognitively oriented. Pharmacologically, these patients can be managed using either sedation or general anesthesia. Behavior-modification therapies aim to change unacceptable behaviors through learning, and involve muscle relaxation and relaxation breathing, along with guided imagery and physiological monitoring using biofeedback, hypnosis, acupuncture, distraction, positive reinforcement, stop-signaling, and exposure-based treatments, such as systematic desensitization, "tell-show-do", and modeling. Cognitive strategies aim to alter and restructure the content of negative cognitions and enhance control over the negative thoughts. Cognitive behavior therapy is a combination of behavior therapy and cognitive therapy, and is currently the most accepted and successful psychological treatment for anxiety and phobia. In certain situations, where the patient is not able to respond to and cooperate well with psychotherapeutic interventions, is not willing to undergo these types of treatment, or is considered dental-phobic, pharmacological therapies such as sedation or general anesthesia should be sought.

Keywords: behavioral therapy, cognitive therapy, general anesthesia, psychotherapeutic intervention, pharmacological intervention, conscious sedation

\section{Introduction}

Fear and anxiety toward the dentist and dental treatment are both significant characteristics that contribute to avoidance of dental care. ${ }^{1,2}$ Anxiety associated with the thought of visiting the dentist for preventive care and over dental procedures is referred to as dental anxiety. It has been cited as the fifth-most common cause of anxiety by Agras et al. ${ }^{3}$ Anxiety is an emotional state that precedes the actual encounter with the threatening stimuli, which sometimes is not even identifiable. It is normally experienced in day-to-day life, such as during exams, while making crucial decisions, in the workplace, and in several other circumstances. 
Fear is a reaction to a known or perceived threat or danger. It leads to a fight-or-flight situation. Dental fear is a reaction to threatening stimuli in dental situations. Phobia is persistent, unrealistic, and intense fear of a specific stimulus, leading to complete avoidance of the perceived danger. Overwhelming and irrational fear of dentistry associated with devastating feelings of hypertension, terror, trepidation, and unease is termed "odontophobia", and has been diagnosed under specific phobias according to the Diagnostic and Statistical Manual of Mental Disorders (DSM)-IV and the International Statistical Classification of Diseases and Related Health Problems (ICD)-10. ${ }^{4}$

Both dental anxiety and fear evoke physical, cognitive, emotional, and behavioral responses in an individual. This is a frequently encountered problem in dental offices. Anxiety is often closely linked to painful stimulus and increased pain perception, and thus these patients experience more pain that lasts longer; moreover, they also exaggerate their memory of pain. ${ }^{5,6}$ Treating such anxious patients is stressful for the dentist, due to reduced cooperation, requiring more treatment time and resources, ultimately resulting in an unpleasant experience for both the patient and the dentist. ${ }^{7,8}$ Eli suggested that a strained dentist-patient relationship dominated by severe anxiety resulted in misdiagnosis during vitality testing for endodontic therapy. ${ }^{9}$

Fearful and anxious individuals feel that something dreadful is going to happen during dental treatment, and hence do not visit the dentist. Such behavior ultimately results in bad oral health, with more missing teeth, decayed teeth, and poor periodontal status. ${ }^{10}$ They present to the dental office only when in acute emergency situations often requiring complicated and traumatic treatment procedures, which in turn further exacerbates and reinforces their fear, leading to complete avoidance in the future. Consequently, a vicious cycle of dental fear sets in if these patients are not managed appropriately (Figure 1). ${ }^{11-14}$

Cohen et al reported that dental anxiety affects an individual's life in multiple ways. The physiological impacts included signs and symptoms of the fright response and feelings of exhaustion after a dental appointment, while the cognitive impacts included an array of negative thoughts, beliefs, and fears. The behavioral impacts included not only avoidance but also other behaviors related to eating, oral hygiene, self-medication, crying, and aggression. A significant impact on general health due to sleep disturbance was also reported, which influenced both established and new personal relationships. Furthermore, social interactions and performance at work were affected, due to feelings of low self-esteem and self-confidence. ${ }^{15}$

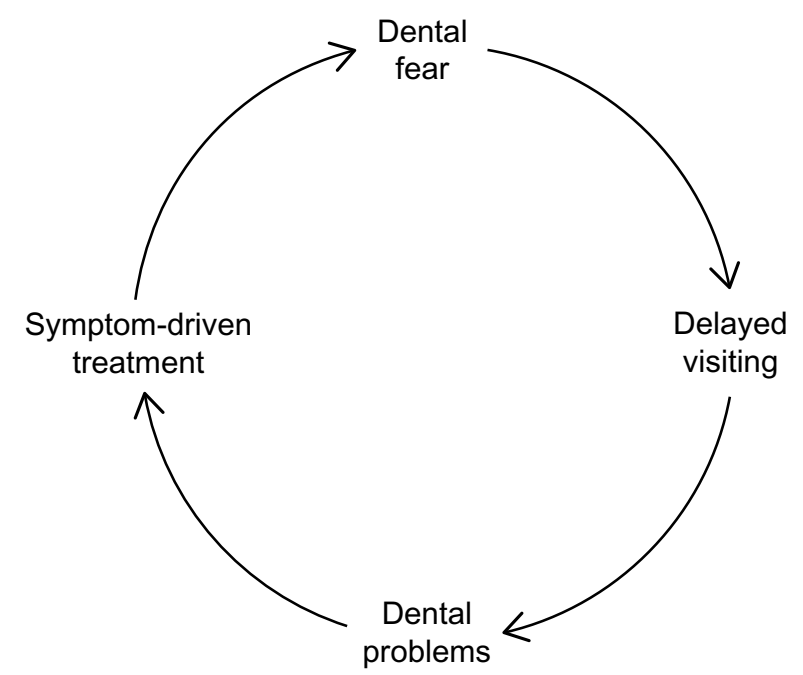

Figure I Vicious cycle of dental fear.

Note: Reproduced from Armfield JM, Stewart JF, Spencer AJ. The vicious cycle of dental fear: exploring the interplay between oral health, service utilization and dental fear. BMC Oral Health. 2007;7:I (http://creativecommons.org/licenses/by/2.0/). ${ }^{14}$

Owing to such widespread significant impacts, it is of utmost importance not only to efficiently identify dentally anxious individuals but also to treat them appropriately when they arrive at the dental office. The practitioner should aim at alleviating the anxiety and fear in such a way that these patients are positively motivated on a long-term basis for future dental visits. This concise review gives an overview of the etiology of dental anxiety, and strategies to identify and manage anxious or phobic individuals in the dental office, with brief literature evidence.

\section{Etiology of dental anxiety}

Dental anxiety can arise due to multiple factors, such as previous negative or traumatic experience, especially in childhood (conditioning experiences), vicarious learning from anxious family members or peers, individual personality characteristics such as neuroticism and self-consciousness, lack of understanding, exposure to frightening portrayals of dentists in the media, the coping style of the person, perception of body image, and the vulnerable position of lying back in a dental chair. ${ }^{16-19}$ Anxiety can also be provoked by sensory triggers such as sights of needles and air-turbine drills, sounds of drilling and screaming, the smell of eugenol and cut dentine, and also sensations of high-frequency vibrations in the dental setting. ${ }^{20-22}$

Some common fears giving rise to dental anxiety are fear of pain, blood-injury fears, lack of trust or fear of betrayal, fear of being ridiculed, fear of the unknown, fear of detached treatment by a dentist or a sense of depersonalization, fear of mercury poisoning, fear of radiation exposure, fear of choking and/or gagging, a sense of helplessness on the 
dental chair, and lack of control during dental treatment. Milgrom et al identified four different groups of anxious patients based on their origin or source of fear (the "Seattle system", developed at the University of Washington). They were 1) anxious of specific dental stimuli, 2) distrust of the dental personnel, 3) generalized dental anxiety, and 4) anxious of catastrophe..$^{23,24}$

\section{Identifying dentally anxious or phobic patients}

The initial interaction of the dentist with the patient can fairly reveal the presence of anxiety and fear, and in such situations, subjective and objective evaluations can greatly enhance the diagnosis for successful management.

\section{Semistructured interview and subjective assessment using questionnaires}

Semistructured interview

The dentist must have a calm, uninterrupted conversation with the patient and try to identify which of the dental situations gives rise to fear and anxiety. Asking a few open-ended questions can help to guide the conversation in the right direction. The dentist needs to identify the reason for the current visit, the kind of experience the patient has had during previous dental treatment, the main fears and worries, and the expectations. Sometimes, the interview may reveal that the dental anxiety is part of a wider psychological disorder. In those cases, it is important that the patient be referred to experts in the field of psychology, such as a psychologist or psychiatrist. They can make the correct psychological diagnosis, and decide what kind of further treatment the patient needs. In some cases, the psychologist and the dentist need to work together, with the former deciding the treatment plan concerning anxiety.

\section{Anxiety questionnaires}

Multiple- and single-item self-reporting questionnaires are available for assessing anxious and phobic patients. A few such popularly used multi-item scales are Corah's Dental Anxiety Scale (CDAS), ${ }^{25}$ Modified Dental Anxiety Scale (MDAS), ${ }^{26}$ Spielberger State-Trait Anxiety Inventory, ${ }^{27}$ Kleinknecht et al's Dental Fear Survey (DFS), ${ }^{28}$ Stouthard et al's Dental Anxiety Inventory, ${ }^{29}$ and Gatchel's 10-point fear scale. ${ }^{30}$ Single-item questionnaires are a Seattle survey item, ${ }^{31}$ the Dental Anxiety Question, ${ }^{32}$ a Finnish single dental anxiety question, ${ }^{33}$ a single-item dental anxiety-and-fear question, ${ }^{34}$ and the visual analog scale. ${ }^{35}$ However, none of these existing instruments has been regarded as a gold standard, as they have their own limitations. The CDAS, MDAS, and DFS are the most commonly used questionnaires, and have been shown to be reliable and valid in multiple languages. ${ }^{34,36}$

The CDAS is a widely used instrument; it is brief and has good psychometric properties. The scale consists of four questions about different dental situations. Each question is scored from 1 (not anxious) to 5 (extremely anxious), so the range of possible scores is $4-20$. The cutoff point of more than 15 indicates high anxiety level or possibly phobic. The major limitation of this scale is that it does not include a question on anxiety regarding local anesthetic injection, and also there is no uniformity in the choices for the questions in the scale, making it difficult to compare the responses. ${ }^{25}$

The MDAS is a brief, well-validated five-item questionnaire with 5-point Likert scale responses to each question, ranging from "not anxious" to "extremely anxious". The responses are scored from 1 to 5 . The score for the scale ranges from a minimum of 5 to a maximum of 25. The higher the score, the higher the dental fear, and a cutoff point for high dental fear has been suggested at a score of 19 , based on clinical relevance. ${ }^{26}$ Humphris and Hull reported that the administration of this questionnaire did not increase anxiety. ${ }^{37}$

The DFS consists of 20 items concerning avoidance behavior, physiological fear reactions, and different fear objects concerning dental appointments and treatment. This questionnaire also has five response options, giving summed scores from a minimum of 20 to a maximum of 100 . A cutoff point for high dental fear has been suggested at $\geq 60$. The scale has three dimensions: avoidance of dental treatment, somatic symptoms of anxiety, and anxiety caused by dental stimuli. $^{28,38}$

Based on these questionnaires, patients can be categorized as mildly anxious, moderately anxious, and extremely anxious or dental-phobic. Literature evidence on the use of such questionnaires in routine clinical practice is very scarce. Dailey et al reported that only $20 \%$ of dentists used these questionnaires in their practice in the UK. ${ }^{39}$ The practitioner should not rely exclusively on clinical judgment in assessing anxious patients, as studies indicate that there is disagreement between patient self-reported anxiety status and clinician rating of dental anxiety; moreover, patients report masking their anxiety, and hence evaluation with brief anxiety questionnaires is beneficial and recommended, as it not only discloses the degree of anxiety but also appears to reduce it, thereby facilitating better management. ${ }^{40}$ Subjective assessment of anxious patients can also be done based on their 
psychophysiological, behavioral, and emotional responses (Table 1).

\section{Objective measures}

Objective measures involve assessment of blood pressure, pulse rate, pulse oximetry, finger temperature, and galvanic skin response. An extremely accurate objective method used in various studies to measure dental anxiety is galvanic skin response. It takes advantage of the electrical changes induced by minute amounts of fluid from epidermal sweat glands released secondary to anxiety. Sweat on the skin provides a low-resistance pathway for electric current, which is then recorded. The use of galvanic skin response has been validated as an accurate method in measuring dental anxiety. ${ }^{41}$

\section{Management of dental anxiety}

The etiology for dental anxiety is multifactorial, and hence there is no monotherapy for management. Proper evaluation of the patient and identifying their source and level of anxiety can enable the dentist in deciding a proper treatment plan. Anxiety can be triggered by even the most innocuous situations, such as the encounter with the receptionist while scheduling their appointments or clinic ambience, and thus it is essential that every aspect of the dental practice be appropriate.

Table I Subjective assessment of anxious patients based on their psychophysiological, behavioral, and emotional responses

\begin{tabular}{ll}
\hline Psychophysiological responses & $\begin{array}{l}\text { Behavioral and } \\
\text { emotional responses }\end{array}$ \\
\hline Muscle tightness & Hyperactivity \\
Hands unsteady & Walking or talking faster \\
Restlessness & In a hurry \\
Clearing the throat & Irritation with delays \\
Sweating of the palms of hands, forehead, & Panicky \\
upper lip (the palm of the hand can be & Blushing \\
assessed during handshake) & Getting tongue-tangled \\
Pulsation in the carotid and temporal arteries & Avoiding people \\
Depth and speed of respiration, & Nervous habits \\
Stiff posture & Poor memory \\
Holding things tightly & Confusion, stumbling \\
Strong startle response & over words \\
Frequent urination & Sitting on the edge of the \\
& chair, leaning forward \\
& Rapidly thumbing \\
through magazines & Pacing \\
Inattentiveness & Excessive worrying \\
& Outburst of emotions \\
\hline
\end{tabular}

Broadly, dental anxiety can be managed by psychotherapeutic interventions, pharmacological interventions, or a combination of both, depending on the dentist's expertise and experience, degree of dental anxiety, patient characteristics, and clinical situations. Psychotherapeutic interventions are either behaviorally or cognitively oriented, and recently, the use of cognitive behavior therapy (CBT) has been shown to be highly successful in the management of extremely anxious and phobic individuals (Table 2). Based on specific indications, these patients can be managed pharmacologically using either sedation or general anesthesia.

\section{The dental office environment}

Dental office ambience can play a significant role in initiating dental fear and anxiety. Receptionists, dental nurses, and dental hygienists are crucial personnel in creating an apt atmosphere in the dental office. They should be positive and caring, and elicit information from the patients in a unhurried concerned tone to make the patients comfortable. The office atmosphere can be made calm and unthreatening by the playing of soft music and avoidance of bright lights. A slightly cooler dental office was preferred by individuals in a study by Bare and Dundes. The walls can be adorned with posters and pictures, the waiting area supplied with ample books and magazines. ${ }^{42}$ The sounds produced from the instruments in the treatment room should be muted by closing the door. Importantly, anxious patients should not be made to wait too long, so that they have less time to absorb

Table 2 Psychotherapeutic interventions

Communication skills, rapport, and trust building: iatrosedative
technique
Behavior-management techniques
Relaxation techniques: deep breathing, muscle relaxation
Jacobsen's progressive muscular relaxation
Brief relaxation or functional relaxation therapy
Autogenic relaxation
Ost's applied relaxation technique
Deep relaxation or diaphragmatic breathing
Relaxation response
Guided imagery
Biofeedback
Hypnotherapy
Acupuncture
Distraction
Enhancing control
"Tell-show-do", signaling
Systematic desensitization or exposure therapy
Positive reinforcement
Cognitive therapy
Cognitive behavioral therapy (CBT)


negative experiences; additionally longer waiting times give them time to recall the threatening stimuli. ${ }^{43,44}$

Introducing pleasant ambient odors to the dental environment can also help to reduce anxiety by masking the smell of eugenol and by the potential anxiolytic effects of the odors themselves. Smell can trigger an array of emotions, and can condition a patient negatively toward dental treatment. Aromatherapy is an alternative treatment approach, wherein essential oils of aromatic plants are used to produce positive physiological or pharmacological effects through the sense of smell. Inhalation of pleasant scents such as essential oils has an anxiolytic effect and improves mood. Studies have shown it to be more efficient in managing moderate rather than severe anxiety. ${ }^{45-47}$ In healthy individuals, inhalation of lavender has been shown to significantly reduce the levels of salivary cortisol, salivary chromogranin, and serum cortisol, increase blood flow, and decrease galvanic skin conductance and systolic blood pressure. . 8,49

A sensory-adapted dental environment (SDE) might also be effective in reducing anxiety and inducing relaxation. ${ }^{50}$ The Snoezelen environment concept aims at stimulating the primary senses of sight, touch, feel, and smell, along with patient-centered therapy. Shapiro et al adapted a "Snoezelen" dental environment for pediatric patients comprised of dimmed lighting, soothing music, and a special Velcro butterfly vest that hugs the child, providing a calming, deep-pressure sensation. Typical children and those with developmental disabilities have been shown to benefit by this SDE, as behavioral and psychophysiological measures of relaxation improved significantly in the SDE compared with a conventional dental environment. ${ }^{51,52}$

\section{Communication skills, rapport, and trust building}

A good patient-dentist relationship is crucial for the management of anxiety. Communication strategies are very important. There should always be two-way communication. The dentist should first introduce themselves and personally converse with the patient in their office, and listen carefully in a calm, composed, and nonjudgmental way. ${ }^{53}$ Proper information should be acquired from the patient regarding their dental problems and concerns, taking time to inquire and listen about their fears (iatrosedative technique). ${ }^{54,55}$ Furthermore, patients should be encouraged to ask questions about the treatment, and should be kept completely informed about what is to be done before starting the procedure and also during the procedure. Keep inquiring if the patients are having any discomfort, give moral support, and reassure during the procedure. The patients should be convinced that their words are taken seriously and with utmost concern. ${ }^{56}$ Dentists should give all the necessary complete information regarding description of the problem, treatment options, and preventive procedures. This meeting should build good rapport and increase the patient's confidence in the dentist. Patients appreciate clear, honest, and straightforward answers; also avoid false reassurances, as these can break trust. Normalizing anxious feelings and avoiding negative phrasing can be beneficial. Nonverbal communications are an essential skill. Touch can be used to comfort and control the patients. The dentist should face the patient, make eye contact, and observe them; this is a positive gesture. Avoid rapid movements, empathize with the patients, and make them feel welcome, and use understandable words when talking about the treatment. Usually, a friendly, sensitive, and sympathetic approach will be well appreciated by patients. ${ }^{57}$

\section{Psychotherapeutic management Behavior-management techniques}

Behavior modification is based on the principles of learning, both in terms of classical conditioning or operant conditioning and of social learning. It aims to change undesirable behavior in certain situations through learning. The strategies involve relaxation along with guided imagery and adjuvant use of physiological monitoring using biofeedback, hypnosis, acupuncture, distraction, positive reinforcement, stopsignaling, and exposure-based treatments, such as systematic desensitization, "tell-show-do", and modeling.

\section{Relaxation techniques}

A relaxation response is the opposite of a stress response, and when practiced regularly it not only lowers stress and anxiety levels but also enables an individual to cope with the symptoms of anxiety. This can be achieved by both deep breathing and muscle relaxation. Once a person is physically relaxed, it is impossible to be psychologically upset at the same time. Anxiety-provoking stimuli give rise to physical tension, which in turn increases the person's perception of anxiety.

Multiple relaxation techniques have been proposed, such as Ost's applied relaxation technique, Jacobsen's progressive muscular relaxation, functional relaxation, the rapidrelaxation technique, autogenic relaxation, and relaxation response. Dentists need to familiarize themselves with these techniques, and if required undergo special training before they can implement them in practice. Once the patient is identified as anxious, these techniques can be taught even before they sit on the dental chair. 


\section{Jacobsen's progressive muscular relaxation}

The most common technique taught to the patient is Jacobsen's progressive muscular relaxation. This involves tensing specific muscle groups for 5-7 seconds, followed by 20 seconds of relaxation. The method can be demonstrated chairside, and should be practiced and rehearsed by the patient at home. Four major muscle groups are commonly tensed and relaxed. These are: 1) feet, calves, thighs, and buttocks; 2) hands, forearms, and biceps; 3) chest, stomach, and lower back; and 4) head, face, throat, and shoulders. Allow 15-20 minutes to practice the relaxation technique. ${ }^{58}$ Step-by-step instructions are given in Table 3.

\section{Brief relaxation or functional relaxation therapy}

Functional relaxation is used for the treatment of a variety of psychosomatic disorders through positive stimulation of the autonomic nervous system. Patients perform minute movements of small joints during relaxed expiration while focusing on perceived changes in bodily feelings triggered by the movements. ${ }^{59,60}$ The structure of brief relaxation therapy is given in Table 4.

Table 3 Jacobson's progressive muscle-relaxation technique

Step-by-step instruction

- Gently breathe in - hold - and let go.

- Gently pull your toes up toward your knees - just a little - hold briefly - and let go. Recognize the difference.

- Press your heels into the floor - hold - and let go.

- Pull your knees together - hold briefly - now let them drift apart a little. Be aware of the new position.

- Squeeze your buttocks together - hold - now let go.

- Gently pull in your tummy muscles toward your spine - hold briefly now let go. Feel the difference.

- Shoulders - gently pull them up toward your ears, just enough to recognise the tension - hold briefly - now let go. Recognise the new position.

- Gently press your elbows and upper arms to the sides of your body hold for a moment - now let go.

- Hands - gently clench - hold - and let go.

- Push your head forward slightly - hold briefly - now let your head go back to a balanced position. Feel the difference.

- Grit your teeth together - hold briefly - now let your jaw sag slightly. Feel the difference.

- Lips - press together - now let go until hardly touching. Purse your lips - now let go and feel the difference.

- Press your tongue briefly to the roof of your mouth - hold - and let it drop loosely. Feel the new position. Eyes - screw them up a little hold - and let go.

- Forehead - frown a little - hold - now let go.

Note: Adapted from Jacobson's progressive relaxation technique. Published by Guy's and St Thomas NHS Foundation Trust (leaflet 2926/VER2). Date published: January 2016; Review date: January 2019.121
Table 4 Brief or functional relaxation therapy instructions

\section{Brief or functional relaxation therapy}

The awareness that you will have to take your place in the dentist's chair in a few minutes quite possibly provokes an unpleasant feeling over your body, leading to a hardening of your muscles. This tension may be relieved by the technique of functional relaxation. For this exercise, please try to feel your body more intensely. Please perform and repeat each sequence of movements as described for 2-3 seconds. Pause for a moment to register your body's perception of changes from one sequence of movements to another. Try to assume a comfortable position in your seat, and perform only small, almost imperceptible, movements.

\section{Instructions}

Let your lower jaw fall loosely and move it easily from right to left for 3-5 seconds.

Move the joints of your head and neck smoothly so that your head nods slightly from one shoulder to the other for 3-5 seconds. Let gravity do the work. Do you notice a change in awareness of your neck?

For 3-5 seconds, move your relaxed shoulders in a circular motion in their joints in such a manner that another person would barely see your movements. Let gravity work for you.

Pay attention to your awareness of your body. Do you notice any variation?

Beginning with your backbone, move like a snake, loosely from side to side and from back to front for 3-5 seconds. Imagine that your chest is suspended from many flexible small joints. Let your ribs fall with gravity. Feel the flexibility of your chest. Notice the sensation inside your chest. Keep in touch with your body and be aware of your bodily experiences. Notice your flexibility.

You do not need to worry about doing something wrong.

\section{Autogenic relaxation}

Autogenic relaxation can be useful in teaching patients to reduce muscle tension and control their breathing. It is defined as a psychophysiological self-control technique that aims at physical and mental relaxation. The technique uses autosuggestions by which patients learn to alter certain psychophysiological functions. Autogenic exercises should be practiced in a quiet room with reduced lighting, so as to exclude the possibility of disturbance, all restricted clothing should be loosened or removed, and the body should be relaxed with the eyes closed, before the mental exercises are begun. It involves mental repetition of brief verbal phrases, emphasizing feelings of 1) general peace, 2) heaviness in the limbs, 3) peripheral warmth, 4) respiratory regularity, 5) cardiac regularity, 6) abdominal warmth, and 7) coolness of the forehead. The technique requires daily training for several weeks. ${ }^{61}$

\section{Ost's applied relaxation technique}

In this technique, patients keep a detailed record of their anxious feelings, especially physical sensations, so that 
they become more aware of them. ${ }^{62}$ The steps followed are given in Table 5.

\section{Deep relaxation or diaphragmatic breathing}

The most important and fundamental way of helping patients to relax physically is to teach them proper breathing techniques. Diaphragmatic breathing is a relaxed form of breathing. Use of the diaphragm for breathing reduces tension in the chest and provides more oxygen for the body per breath. ${ }^{63}$ The technique can be done as follows:

1. sit up straight; head should be upright not hanging forward or tilted back

2. rest one hand on your chest and the other hand on your abdomen

3. next, blow out all the air in your lungs until you feel empty

4. then begin to breathe in; inhaling must be done evenly: count your breathing until you feel exactly full, to help you get a measured, even breath

5. exhale evenly: count the breath out of your body, without any sudden release

6. exhale longer than you inhale.

It is recommended to use relaxation breathing and muscle relaxation simultaneously. The patient is supposed to tense a specific set of muscles during inhaling, and then to relax them during exhaling. Guided imagery and biofeedback can also be combined with relaxation techniques.

\section{Relaxation response}

Herbert Benson at Harvard Medical School demonstrated that meditation is another efficient technique that allows greater control over the peripheral nervous system and

Table 5 Ost's applied relaxation technique

In this technique, the patients keep a detailed record of their anxious feelings, especially physical sensations, so that they become aware of them. Then they learn to practice the following steps:

I. Tension-release progressive relaxation: the patient is asked to tense a group of muscles for approximately 20 seconds and then release the tension.

2. Release-only relaxation: the patient is asked to only relax a group of muscles.

3. Cue-controlled relaxation: in this step, the patient is asked to link release-only relaxation to breathing. As they breathe in, they are told to think "in", and as they breathe out to think "relax" and release tension at the same time, and to practice this daily and achieve a relaxed state in 2-3 minutes.

4. Differential relaxation-practice relaxation in different situations.

5. Rapid relaxation-practice relaxation in a more natural surrounding and attempt to quicken the pace of the relaxation process.

6. In the final step the patient is made to practice relaxation under the stress of clinic situation.

Note: Data taken from Ost. ${ }^{62}$ central nervous system (CNS). It is based on transcendental meditation. He hypothesized that relaxation is hypothalamically mediated, and is a counterbalancing mechanism to the stress response. There are four elements necessary to elicit the relaxation response: relaxed musculature, a quiet environment, passive disregard of everyday thought, and the focus of attention on a repetitive mental stimulus, such as a word, a sound, a phrase, or even repetitive breathing. Regular elicitation of the relaxation response appears to diminish the effects of the stress response, and is also effective in the treatment of many health problems. ${ }^{64-66}$

\section{Guided imagery}

Guided imagery has been defined as a directed, deliberate daydream that uses all the senses to create a focused state of relaxation and a sense of physical and emotional well-being. It is a mind-body exercise, wherein patients are taught to develop a mental image of a pleasant, tranquil experience that consciously guides their attention to achieve relaxation, thereby reducing anxiety. There are generally three stages to guided imagery: relaxation, visualization, and positive suggestion. ${ }^{67}$ Imagery can be a pleasant place such as a beach, mountains, lake, or a safe place, and should be engaging and customized to each patient. Patients can be allowed to choose their own mental image or they can be guided by using scripts by the dentist. They are instructed to create a scenario full of specific, concrete details, along with sound, smell, and colors of the scene. This technique produces wonderful, soothing relaxation throughout the body. It can be used along with relaxation techniques and CBT. Studies have shown the effectiveness of guided imagery in the treatment of distress, mood, and anxiety symptoms associated with chronic pain, social anxiety disorder, attention deficit/hyperactivity disorder, and cancer pain. ${ }^{68,69}$ It is relatively easy to learn, teach, and use in practice. It can be performed by an adequately trained dentist or with the use of audio recordings, and can be performed daily or as needed by the patient.

\section{Biofeedback}

Biofeedback is also referred to as applied psychophysiological feedback, and is a mind-body technique. Biofeedback therapies use instruments to measure, amplify, and feed back physiological information to the patient being monitored. The information assists the patient in gaining self-regulation of the physiological process being monitored. Monitoring oneself and then utilizing the information to practice and achieve selfregulation are the main goals of biofeedback. Milgrom et al 
showed that it is efficient in clinical settings..$^{70,71}$ Reduction of muscle-tension levels through electromyographic biofeedback and operant conditioning of brain-wave activity through electroencephalographic biofeedback are commonly used for reducing anxiety. Recently, the use of respiratory ratebiofeedback device has been shown to reduce preoperative general anxiety levels. ${ }^{72,73}$ Implementing this technology into practice would require not only special instruments but also a trained dentist.

\section{Hypnotherapy}

Clinical hypnosis (from the Greek hypnos [sleep]), although criticized and misunderstood, has been successfully used in medicine and dentistry. The term "hypnosis" denotes an interaction between one person - the "hypnotist" - and another person or people - the "subjects". In this interaction, the hypnotist attempts to influence the subjects' perceptions, feelings, thinking, and behavior by asking them to concentrate on ideas and images that may evoke the intended effects. The verbal communications that the hypnotist uses to achieve these effects are termed "suggestions". Suggestions differ from everyday kinds of instructions in that they imply that a "successful" response is experienced by the subject as having a quality of involuntariness or effortlessness. ${ }^{74}$ They can be used to induce relaxation, as an adjunct to inhalation sedation, to alleviate pain, anxiety, and stress, in reducing problems with excessive gag reflex, and may also be a part of CBT. The techniques have pre- and postsuggestion components. The presuggestion component involves attentional focusing through the use of imagery, distraction, or relaxation, and is similar to other relaxation techniques. Subjects focus on relaxation, and passively disregard intrusive thoughts. The postsuggestion component involves the continued use of the new behavior following the termination of hypnosis. Individuals widely vary in their hypnotic susceptibility and suggestibility, although the reasons for these differences are incompletely understood. It is inexpensive, and has a very low risk of side effects. The technique needs to be avoided in those with mental health problems, personality disorders, and neurodegenerative disorders. Dentists require special training before they can practice hypnotherapy.

In a meta-analytic review, it was shown that $75 \%$ of subjects experienced pain reduction following hypnosis. Studies have also shown effectiveness in anxiety reduction, allowing people to handle stressful dental treatments. ${ }^{75,76}$ More studies are required to validate the practicality and effectiveness of hypnosis on a routine basis in dental clinical settings.

\section{Acupuncture}

Acupuncture is a technique, ${ }^{89}$ wherein the disease is treated by inserting needles at various points on the body, known as acupuncture points. It has been reported that acupuncture is effective in treating dental problems such as anxiety, temporomandibular dysfunction syndrome, pain, and Sjögren's syndrome. It is a simple, inexpensive treatment modality that requires special training before it can be incorporated into practice. Reports on the use of auricular acupuncture for treating chronic and acute anxiety have shown promising results. ${ }^{77,78} \mathrm{~A}$ randomized controlled trial comparing auricular acupuncture with intranasal midazolam for managing dental anxiety suggested that both treatment methods were similarly effective. ${ }^{79}$ Though inconclusive, systematic reviews have suggested acupuncture as a promising therapy for the management of anxiety disorders in a dental setting. ${ }^{80,81}$ In a recent systematic review and meta-analysis on the effect of acupressure on anxiety, Au et al concluded that it was effective in providing immediate relief of pretreatment anxiety among adults and had a medium effect size. However, conflicting results were found for improvements on physiological indicators. ${ }^{82}$

\section{Distraction}

Distraction is a useful technique of diverting the patient's attention from what may be perceived as an unpleasant procedure. This enables decreased perception of unpleasantness and averting negative or avoidance behavior. Giving the patient a short break during a stressful procedure can be an effective use of distraction prior to considering more advanced behavior-guidance techniques. ${ }^{83}$ Several technological options are available for both visual and auditory distraction, such as background music, television sets, computer games, and 2-D and 3-D video glasses for watching movies. ${ }^{83,84}$

Suitable music has been shown to influence human brain waves, leading to deep relaxation and alleviating pain and anxiety. Music distraction is a noninvasive technique in which the patient listens to pleasant music during a stressful procedure. The effect is believed to be a combination of relaxation and distraction that in turn reduces the activity of the neuroendocrine and sympathetic nervous systems. It has been successful in both pediatric and adult dental patients. ${ }^{85,86}$ Music therapy can be either active or passive. The former involves a music therapist with interactive communication, while the latter involves passive listening to prerecorded music. 


\section{Enhancing control}

Loss of control over the treatment procedure is a significant cause for anxiety, and hence providing control is very essential. Telling the patient what to expect, and what measures are taken to ensure their safety, will help make the treatment as comfortable as possible. Control can be provided by giving information and through behavioral control. Informational control can be achieved by the "tell-show-do" and modeling techniques.

Tell-show-do is a behavior-shaping technique that reduces uncertainty and increases predictability in the clinical setting. ${ }^{83}$ This technique can be used for both child and adult patients. It involves verbal explanations of procedures in phrases appropriate to the developmental level of the patient (tell); demonstrations for the patient of the visual, auditory, olfactory, and tactile aspects of the procedure in a carefully defined, unthreatening setting (show); and then, without deviating from the explanation and demonstration, completion of the procedure (do). The tell-show-do technique is used with communication skills (verbal and nonverbal) and positive reinforcement. ${ }^{87}$

Individuals learn much about their environment from observing the consequences of other people's behavior. Modeling is a technique used to alleviate anxiety. This can be achieved through observation of a dental procedure, either by viewing a videotaped model who is demonstrating appropriate cooperative behavior in the dental setting or through observation of an actual successful dental procedure. This could reduce anxiety due to "fear of the unknown", and demonstrates to the anxious patient what is considered appropriate behavior in the dental setting and what can be expected in the upcoming treatment session. When setting up a program, the following details should be taken care of: the model should be close to the age of the patient, the model should be shown entering and leaving the surgery to prove treatment has no lasting effect, and the dentist should be shown to be a caring person who praises the patient. ${ }^{88}$

Behavioral control involves giving the patient a chance to feel that they are in control of the treatment procedure. It involves signaling to the dentist or dental hygienist to stop the procedure; this increases the patients' sense of control and trust in the dentist. A signal can be as simple as a raised hand to notify the dental practitioner that the patient would like to stop the procedure. Specific signals can be decided before the treatment commences. The dentist should stop the procedure as agreed earlier; failure to do so will breach the trust relationship. Patients can also be given mirrors to watch the procedure, so as to feel they are in control. ${ }^{24}$

\section{Systematic desensitization or exposure therapy}

Wolpe's technique ${ }^{89}$ known as systematic desensitization, is based on relaxation and played a very prominent role in the evolution of behavior therapy during the 1960s and 1970s. The treatment procedure is carried out in multiple sessions. The use of systematic desensitization involves three sets of activities. Encourage the patients to discuss their status of fear and anxiety, in order to construct a hierarchy of feared dental situations, from the least to the most anxiety-provoking. Teach the patient relaxation techniques. The most commonly used techniques are breathing and muscle relaxation. The final step is to gradually expose the patient to these situations in the hierarchy, from the least to the most anxiety-promoting. ${ }^{24,88,89}$

When it is difficult to expose the patient directly to the dental setting, it may be appropriate to instruct the patients to practice imaginary systematic desensitization, wherein the patients are encouraged to imagine that they are entering the dental clinic, able to sit in the dental chair, and eventually able to receive dental treatment. Flooding or implosion therapy is an intensive form of in vivo exposure therapy for treating phobias. The patient is confronted with the feared stimuli for repeated and prolonged duration until they experience a reduction in their anxiety level. The use of this technique requires more caution, due to adverse effects and limited evidence in the literature..$^{90}$

\section{Positive reinforcement}

Positive reinforcement is an effective technique to reward desired behaviors and thus strengthens the recurrence of those behaviors. Reinforcers include positive voice modulation, facial expression, verbal praise, and appropriate physical demonstrations of affection by all members of the dental team. These should be individualized, frequently provided, and varied over time. ${ }^{91}$

\section{Cognitive therapy}

The thoughts and emotions of a person are not separate; rather, they overlap each other and behavior depends on their thoughts. Thoughts and expectations trigger different feelings and physiological reactions. Anxious patients most often have inappropriate expectations and beliefs about dental treatment. The modification of such negative cognitions is a means of reducing anxiety. Cognitive treatment strategies aim to alter and restructure the content of negative cognitions and enhance control over the negative thoughts. The patient's focus is directed away from his or her worries about the feared situation by using different cognitive techniques, such 
as encouragement, altering expectations, distraction, guided imagery, focusing attention, and thought stopping..$^{92,93}$

CBT is a combination of behavior therapy and cognitive therapy. It is today the most accepted psychological treatment for anxiety related to particular situations and specific phobias. It involves learning to change negatively distorted thoughts (cognitions) and actions (behaviors). Basically, new skills are learned to manage anxiety symptoms over multiple sessions with the therapist. It is structured, problem-focused, goal-oriented, teaches proven strategies and skills, and lastly emphasizes the importance of a good, collaborative therapeutic relationship between the therapist and the patient. ${ }^{94,95}$ CBT treatment generally contains psychoeducation, graded exposure, cognitive restructuring, behavioral experiments, and relaxation, as well as self-assertiveness training. Selfassertiveness training aims to improve fearful patients' communication skills concerning personal opinions, feelings, and needs during dental treatment. Case reports, systematic reviews, and meta-analyses indicate that CBT is effective in reducing dental anxiety and phobia. Dentists need special training to integrate this therapy in practice. ${ }^{96,97}$

\section{Technological advancements in local anesthetic administration that help alleviate anxiety Computer-controlled local anesthetic delivery}

This system represents a significant change in the manner in which a local anesthetic injection is administered, thereby alleviating anxiety in patients who fear injections or are needlephobic. It is essentially a computer-controlled dental injection. The flow rate of the local anesthetic is controlled by a computer. A plastic handpiece is less threatening in appearance than the traditional syringe. Injecting local anesthetic solution slowly reduces tissue distension and leads to a more comfortable injection with less postoperative pain. The greater control over the syringe and the fixed flow rate of the drug are responsible for a significantly improved injection experience, as demonstrated in many clinical studies conducted with computer-controlled local anesthetic delivery devices in dentistry. ${ }^{98-100}$ A growing number of clinical trials in medicine have also demonstrated measurable benefits of this technology. ${ }^{98-100}$

\section{Electronic dental anesthesia}

This technique is used to produce dental anesthesia by using the principle of transcutaneous electric nerve stimulation. By means of electrodes, electric flow from the stimulation unit is converted into an ionic current flow in the living tissue and anesthesia is produced, offering pain control without needles, based on the gate-control theory of pain. Electrodes can be placed either extraorally or intraorally. The intraoral electrodes are cotton-roll electrodes, clamp electrodes, and adhesive electrodes. Adhesive electrodes are the most widely used. These electrodes are thin and flexible, and so can easily adapt to the oral mucosa. The technique is noninvasive, safe, and generally well accepted by the patient. Advantages of electronic dental anesthesia are as follows: there is no need for a needle, no need for injection of drugs, limited soft-tissue anesthesia, the residual analgesic effect remains for several hours, it is suitable for the needle-phobic, and there is no residual anesthetic effect at the end of the procedure. Disadvantages are the high cost of the unit are as follows: it is not suitable for all patients and all treatments, efficacy is not as predictable as with other methods of anesthesia, it requires training, and there is a learning curve, whereby initially the success rate may be low but then it increases with experience. Some studies have proposed electronic dental anesthesia to be effective and efficacious in pain control, but there are contradictions with questionable efficacy. ${ }^{101-103}$

\section{Computer-assisted relaxation learning}

Computer-assisted relaxation learning is a program developed to reduce fear of dental injections. It is a computer-based application utilizing principles of CBT. Individuals view a series of videos in which a fearful patient is taught coping skills and then taken through the gradual steps of a dental injection. A randomized controlled trial by Heaton et al ${ }^{104}$ suggested that computer-assisted relaxation learning led to significant changes in self-reported fear of dental injections in the study participants. ${ }^{98}$ A systematic review by Patel et al indicated that the overall quality of evidence for psychological treatment for injection fear or phobia is poor, and outcome measures need consensus and further development. ${ }^{105}$

Jet injections and vibrotactile devices are other modern gadgets available for local anesthetic administration. Whether these devices are efficient in alleviating anxiety and phobia needs more exploration with randomized controlled clinical trials.

\section{Technological advancements that help alleviate anxiety in restorative dentistry}

Anxious patients who must undergo restorative procedures are often managed using the " $4 \mathrm{~S}$ " rule or the so-called $4 \mathrm{~S}$ 
principle. This is based on eliminating four of the primary sensory triggers for dental anxiety when in the dental setting: sight (air-turbine drill, needles), sounds (drilling), sensations (high-frequency vibrations [the annoyance factor]), and smells. ${ }^{21,106}$ Newer methods, such as atraumatic restorative treatment, air abrasion using alumina powder streams, ultrasonic tips coated with diamond particles, chemomechanical caries removal targeting collagen in infected dentine, which are susceptible to proteolysis by sodium hypochlorite and chloramines, and lasers for cavity preparation, may reduce painful or uncomfortable aspects of dentistry, thereby reducing anxiety and fear of pain during treatment.

\section{Pharmacological management Indications}

Pharmacological control of pain and anxiety can be achieved by the use of sedation and general anesthesia, and should be sought only in situations where the patient is not able to respond and cooperate well with psychotherapeutic interventions, is not willing to undergo this type of treatment, or is considered dental-phobic. Patients with special needs (mental retardation, autism, mental illness, traumatic brain injury) and clinical situations can also necessitate pharmacological management. ${ }^{107,108}$

There are a few factors to be considered prior to pharmacological management:

1. risks involved with pharmacological management when compared to behavioral therapies

2. appropriate evidence-based selection of drugs for pharmacological management

3. extent of the patient's dental needs and severity of anxiety

4. patient's cognitive and emotional needs and personality

5. practitioner skill, training, and experience

6. proper equipment and monitoring

7. cost of the procedure.

\section{Indicator of sedation needs tool}

This is an adjunct tool developed to support clinicians in deciding about need for conscious sedation. It has three indicators: anxiety, medical and behavioral, and treatment complexity. Scores for each of these indicators range from 1 to 4 . Final scores sum to $3-12$. A score of 3 or 4 indicates minimal need for sedation, 5 or 6 moderate need, 7-9 high need, and 10-12 suggests very high need or even use of general anesthesia. ${ }^{109}$

Sedation is defined as the use of a drug or combination of drugs to depress the CNS, thus reducing patient awareness of their surroundings. Depending on the degree of CNS suppression, the sedation may be conscious, deep, or general. Sedation does not control pain, and consequently does not eliminate the need for the use of local anesthetics. According to the American Society of Anesthesiologists (ASA; Table 6), patients should fulfill the demands of being classified as category ASA I (mentally and physically healthy) or ASA II (only mild systemic disease, which does not result in any functional limitation), in order to be considered a candidate for sedation. Sedation is a continuum that proceeds from minimal to deep in a dose-response manner. This continuum can be divided into levels with characteristics that have been used to design several subjective sedation scales (Table 7).

Minimal sedation/anxiolysis is a drug-induced state during which patients respond normally to verbal commands. Although cognitive function and physical coordination may be impaired, airway reflexes and ventilator and cardiovascular functions are unaffected. This level is achieved with either oral sedatives alone or in combination with nitrous oxide and oxygen. This is used for managing patients with mild-to-moderate anxiety.

Moderate/conscious sedation is a drug-induced depression of consciousness during which patients respond purposefully to verbal commands, either alone or accompanied by light tactile stimulation. No interventions are required to maintain a patent airway, and spontaneous ventilation is adequate. Cardiovascular function is usually maintained. This is used for managing patients with moderate-to-severe anxiety.

Deep sedation is a drug-induced depression of consciousness during which patients cannot be easily aroused but respond purposefully following repeated or painful stimulation. Ability to maintain ventilatory function independently may be impaired. Patients may require assistance in maintaining a patent airway, and spontaneous ventilation may be inadequate. Cardiovascular function is usually maintained. ${ }^{110,111}$

General anesthesia is a drug-induced loss of consciousness during which patients are not arousable, even by painful

Table 6 American Society of Anesthesiologists (ASA) physical status classification

ASA I - normal healthy patient

ASA II - patient with mild systemic disease

ASA III - patient with severe systemic disease

ASA IV - patient with severe systemic disease that is a constant threat to life

ASA V - moribund patient who is not expected to survive without the operation

ASA VI - patient declared brain-dead whose organs are being removed for donor purposes

$\mathrm{E}$ - emergency operation of any variety (used to modify one of the aforementioned classifications, ie, ASA III-E) 
Table 7 Continuum of depth of sedation: definition of general anesthesia and levels of sedation/analgesia

\begin{tabular}{llll}
\hline & $\begin{array}{l}\text { Minimal sedation } \\
\text { (anxiolysis) }\end{array}$ & $\begin{array}{l}\text { Moderate sedation/analgesia } \\
\text { (conscious sedation) }\end{array}$ & Deep sedation/analgesia \\
\hline Responsiveness & Normal response to & Purposeful response to verbal & Purposeful response following \\
& verbal stimulation & or tactile stimulation & Not arousable, even with \\
Airway & Unaffected & No intervention required & Intervention may be required \\
Spontaneous ventilation & Unaffected & Adequate & May be inadequate \\
Cardiovascular function & Unaffected & Usually maintained & Usually maintained
\end{tabular}

stimulation. The ability to maintain ventilatory function independently is often impaired. Patients often require assistance in maintaining a patent airway, and positive pressure ventilation may be required because of depressed spontaneous ventilation or drug-induced depression of neuromuscular function. Cardiovascular function may be impaired.

Dental-phobic patients and those with severe learning difficulties, severe anxiety and phobias, severe psychiatric disorders, physical disability and movement disorders, and significant comorbidity, such as those with congenital disorders, in whom sedation may not be safe and perioperative monitoring is required, are candidates for general anesthesia in special care dentistry.

\section{Conscious sedation}

This is a technique in which the use of a drug or drugs produces a state of depression of the CNS, enabling treatment to be carried out, but during which verbal contact with the patient is maintained throughout the period of sedation. The drugs and techniques used to provide conscious sedation for dental treatment should carry a margin of safety wide enough to render loss of consciousness unlikely. Based on the routes of administration, conscious sedation techniques are inhalational, intravenous (IV), oral, sublingual, intranasal, intramuscular, or rectal. A thorough medical, dental, and social history must be taken and recorded to ensure that the conscious sedation technique chosen is the most appropriate to enable successful treatment outcomes for each individual, taking into account such factors as the patient's age, state of health, social circumstances, and any special needs they may have. Sedation should not be used habitually when there is no specific indication. ${ }^{12,113}$

The dentist and the dental team should be adequately trained and be familiar with appropriate regulations according to the country of practice. Each country has its own guidelines and advice on special training for dentists.

\section{Inhalation sedation}

This is a commonly used technique for dental sedation. A mixture of nitrous oxide $\left(\mathrm{N}_{2} \mathrm{O}\right)$ and oxygen is used.
Nitrous oxide has an anxiolytic and sedative effect, and also promotes muscular relaxation and analgesia. It is nonirritant for the respiratory tract, with minimal alveolar concentration and low solubility in tissues. It acts with a quick onset and rapid recovery, the entire procedure lasting only a few minutes. As a rule, $70 \%$ of patients will need $30 \%-40 \%$ nitrous oxide to achieve sedation. In most purpose-built equipment, there is an inbuilt safety feature that does not allow more than $70 \%$ nitrous oxide to be delivered to the patient. Most of the disadvantages of nitrous oxide relate to equipment and the logistics of safe delivery, such as operative space, cost of the equipment and supplies, and cost to the patient.

Oral sedation is an enteral technique of administration in which the drug is absorbed through the gastrointestinal tract. It is often used for the management of mild-to-moderate anxiety, and in some cases to assist the patient to have a restful night prior to the appointment. It may also be used or as an adjunct to other methods of sedation for the severely anxious. The goal is to produce a lightly sedated, relaxed, more cooperative patient that is easier to manage. Benzodiazepines are commonly used. The benzodiazepines have antianxiety, sedative-hypnotic, anticonvulsant, and skeletal muscle-relaxant properties. They exert their sedative effects by a generalized depression of the CNS. Commonly used drugs in this class are diazepam, midazolam, and triazolam.

IV sedation entails the administration of sedative agents directly into the vascular compartment. The use of IV sedation in a dental office requires additional advanced training. The main advantages of the IV route are rapid onset of action and ability to titrate to effect and control the duration of sedation. Other advantages include higher levels of efficacy than oral or inhalation sedation and IV access for emergency drugs or reversal agents if needed. The most common parenteral sedation technique involves the use of a benzodiazepine (eg, diazepam or midazolam) alone or in combination with an opioid (eg, fentanyl or Demerol).

Berggren identified four specific situations where CBT can be combined with pharmacological treatment: ${ }^{114}$ 
1. When the patient has an immediate need for dental treatment because of acute dental pain. It is difficult to motivate the patient to work with their anxiety in painful conditions. Nitrous oxide sedation, or oral/IV sedation with benzodiazepines is typically the first choice, and sometimes general anesthesia may be needed.

2. When the patient has need of multiple and complex treatment with increased risk for acute dental pain. These patients are so preoccupied by their need for dental treatment that they cannot deal with their underlying fear or anxiety. They can be managed under general anesthesia, later followed by psychological anxiety-reducing therapies.

3. When the patient is referred to the clinic specifically for general anesthesia treatment, and categorically demands it. These patients may be motivated for anxiety treatment afterward.

4. When it may be strategic for highly motivated patients to start exposure therapy aided by mild sedation.

\section{Psychological intervention versus pharmacological intervention}

Psychological and pharmacological interventions are both equally effective in reducing dental anxiety and phobia. Response to behavioral and cognitive therapy is not immediate, and multiple sessions are usually needed to maintain an initial treatment response; however, studies have shown that dropout rates were low and reduction in anxiety or phobia was maintained over longer time periods, with more patients reporting back for future treatment. ${ }^{114-117}$ Pharmacological approaches are seen as less acceptable by patients when compared to psychological techniques, and have been shown to be effective on only a short-term basis. ${ }^{118-120}$

\section{Conclusion}

Dental anxiety and phobia can have adverse impacts on a person's quality of life, and hence it is imperative to identify and alleviate these significant obstacles to pave the way for better oral health and overall well-being of the individual. It is the duty and responsibility of the dentist to provide excellent dental care to these patients with special needs as well. Management of these patients should be an integral part of clinical practice, as a substantial proportion of the population suffers from anxiety and fear. Therapy should be customized to each individual following proper evaluation, and should be based on the dentist's experience, expertise, degree of anxiety, patient intellect, age, cooperation, and clinical situation. The dentist should communicate with the patient and identify their source of fear and anxiety, with adjuvant use of self-reporting anxiety and fear scales to enable categorization as mild, moderate, or extreme anxiety or dental-phobic. Manifold psychological therapies are employed to mollify emotional, cognitive, behavioral, and physiological dimensions of dental anxiety and fear. These therapies are efficient on a long-term basis with positive effects on the patients, enabling them to seek dental care in future, which should be the primary focus of the dental team. Mildly and moderately anxious patients can be frequently managed using psychological interventions, and occasionally anxiolytic drugs or conscious sedation may be necessary. Extremely anxious or phobic patients most frequently require combined management approaches. Due to the high risk involved in pharmacological interventions, it is mandatory that the dentist and dental team follow proper guidelines and be adequately trained and sufficiently equipped with proper infrastructure before pharmacological interventions can be incorporated. All successful treatment will rest on dentist-patient cooperation, and thus a relaxed patient will obviously result in a less stressful atmosphere for the dental team and better treatment outcomes.

\section{Disclosure}

The author reports no conflicts of interest in this work.

\section{References}

1. Pohjola V, Lahti S, Vehkalahti MM, Tolvanen M, Hausen H. Association between dental fear and dental attendance among adults in Finland. Acta Odontol Scand. 2007;65(4):224-230.

2. Gatchell RJ, Ingersoll BD, Bowman L, Robertson MC, Walker C. The prevalence of dental fear and avoidance: a recent survey study. $J \mathrm{Am}$ Dent Assoc. 1983;107(4):609-610.

3. Agras S, Sylvester D, Oliveau D. The epidemiology of common fears and phobia. Compr Psychiatry. 1969;10(2):151-156.

4. Berggren U, Hakeberg M, Carlsson SG. No differences could be demonstrated between relaxation therapy and cognitive therapy for dental fear. J Evid Based Dent Pract. 2001;1(2):117-118.

5. Weisenberg M, Aviram O, Wolf Y, Raphaeli N. Relevant and irrelevant anxiety in the reaction to pain. Pain. 1984;20(4):371-383.

6. Al Absi M, Rokke PD. Can anxiety help us tolerate pain? Pain. 1991; 46(1):43-51

7. Moore R, Brødsgaard I. Dentists' perceived stress and its relation to perceptions about anxious patients. Community Dent Oral Epidemiol. 2001;29(1):73-80.

8. Brahm CO, Lundgren J, Carlsson SG, Nilsson P, Corbeil J, Hägglin C. Dentists'views on fearful patients. Problems and promises. Swed Dent J. 2012;36(2):79-89.

9. Eli I. Dental anxiety: a cause for possible misdiagnosis of tooth vitality. Int Endod J. 1993;26(4):251-253.

10. van Wijk AJ, Hoogstraten J. The Fear of Dental Pain questionnaire: construction and validity. Eur J Oral Sci. 2003;111(1):12-18.

11. Armfield JM, Spencer AJ, Stewart JF. Dental fear in Australia: who's afraid of the dentist? Aust Dent J. 2006;51(1):78-85.

12. Eitner S, Wichmann M, Paulsen A, Holst S. Dental anxiety - an epidemiological study on its clinical correlation and effects on oral health J Oral Rehabil. 2006;33(8):588-593. 
13. Armfield JM, Slade GD, Spencer AJ. Dental fear and adult oral health in Australia. Community Dent Oral Epidemiol. 2009;37(3): 220-230.

14. Armfield JM, Stewart JF, Spencer AJ. The vicious cycle of dental fear: exploring the interplay between oral health, service utilization and dental fear. BMC Oral Health. 2007;7:1.

15. Cohen SM, Fiske J, Newton JT. The impact of dental anxiety on daily living. Br Dent J. 2000;189(7):385-390.

16. Locker D, Shapiro D, Liddell A. Overlap between dental anxiety and blood-injury fears: psychological characteristics and response to dental treatment. Behav Res Ther. 1997;35(7):583-590.

17. Seeman K, Molin C. Psychopathology, feelings of confinement and helplessness in the dental chair, and the relationship to the dentist in patients with disproportionate dental anxiety (DDA). Acta Psychiatry Scand. 1976;54(2):81-91.

18. Benjamin C, Schuurs AH, Kooreman T, Hoogstraten J. Self-reported and physiologically measured dental anxiety, coping styles and personality traits. Anxiety Stress Coping. 1996;9(2):151-162.

19. Ost LG, Hugdahl K. Acquisition of blood and dental phobia and anxiety response in clinical patients. Behav Res Ther. 1985;23(1):27-34.

20. Oosterink FM, de Jongh A, Aartman IH. What are people afraid of during dental treatment? Anxiety-provoking capacity of 67 stimuli characteristic of the dental setting. Eur J Oral Sci. 2008;116(1):44-51.

21. Walsh LJ. Anxiety prevention: implementing the $4 \mathrm{~S}$ principle in conservative dentistry. Auxiliary. 2007;17(5):24-26.

22. Hmud R, Walsh LJ. Dental anxiety: causes, complications and management approaches. J Minim Interv Dent. 2009;2(1):67-78.

23. Milgrom P, Weinstein P, Getz T. Treating Fearful Dental Patients: A Patient Management Handbook. Seattle: Reston Prentice Hall; 1995.

24. Armfield JM, Heaton LJ. Management of fear and anxiety in the dental clinic: a review. Aust Dent J. 2013;58(4):390-407.

25. Corah NL. Development of a dental anxiety scale. J Dent Res. 1969;48(4):596.

26. Humphris GM, Morrison T, Lindsay SJ. The Modified Dental Anxiety Scale: validation and United Kingdom norms. Community Dent Health. 1995;12(3):143-150.

27. Spielberger CD. Assessment of state and trait anxiety: conceptual and methodological issues. South Psychol. 1985;2(4):6-16.

28. Kleinknecht RA, Klepac RK, Alexander LD. Origins and characteristics of fear of dentistry. J Am Dent Assoc. 1973;86(4):842-848.

29. Stouthard ME, Mellenbergh GJ, Hoogstraten J. Assessment of dental anxiety: a facet approach. Anxiety Stress Coping. 1993;6(2):89-105.

30. Gatchel RJ. The prevalence of dental fear and avoidance: expanded adult and recent adolescent surveys. J Am Dent Assoc. 1989;118(5): 591-593.

31. Moore R, Birn H, Kirkegaard E, Brødsgaard I, Scheutz F. Prevalence and characteristics of dental anxiety in Danish adults. Community Dent Oral Epidemiol. 1993;21(5):292-296.

32. Neverlien PO. Dental anxiety, optimism-pessimism, and dental experience from childhood to adolescence. Community Dent Oral Epidemiol. 1994;22(4):263-268.

33. Viinikangas A, Lahti S, Yuan S, Pietilä I, Freeman R, Humphris G. Evaluating a single dental anxiety question in Finnish adults. Acta Odontol Scand. 2007;65(4):236-240.

34. Armfield JM. A comparison of three continuous scales used to determine the prevalence of clinically significant dental fear. Community Dent Oral Epidemiol. 2011;39(6):554-563.

35. Luyk NH, Beck FM, Weaver JM. A visual analogue scale in the assessment of dental anxiety. Anesth Prog. 1988;35(3):121-123.

36. Armfield JM. How do we measure dental fear and what are we measuring anyway? Oral Health Prev Dent. 2010;8(2):107-115.

37. Humphris G, Hull P. Do dental anxiety questionnaires raise anxiety in dentally anxious adult patients? A two-wave panel study. Prim Dent Care. 2007;14(1):7-11.

38. McGlynn FD, Harkavy J. Factor analysis of the dental fear survey with cross-validation. J Am Dent Assoc. 1984;108(1):59-61.
39. Dailey YM, Humphris GM, Lennon MA. The use of dental anxiety questionnaires: a survey of a group of UK dental practitioners. Br Dent $J$. 2001;190(8):450-453.

40. Lahti S, Tuutti H, Hausen H, Kääriäinen R. Comparison of ideal and actual behavior of patients and dentist during dental treatment. Community Dent Oral Epidemiol. 1995;23(6):374-378.

41. Caprara HJ, Eleazer PD, Barfield RD, Chavers S. Objective measurement of patient's dental anxiety by galvanic skin reaction. $J$ Endod. 2003;29(8):493-496.

42. Bare LC, Dundes L. Strategies for combating dental anxiety. J Dent Educ. 2004;68(11):1172-1177.

43. Lehrner J, Eckersberger C, Walla P, Potsch G, Deecke L. Ambient odor of orange in a dental office reduces anxiety and improves mood in female patients. Physiol Behav. 2000;71(1):83-86.

44. Lehrner J, Marwinski G, Lehr S, Johren P, Deecke L. Ambient odors of orange and lavender reduce anxiety and improve mood in a dental office. Physiol Behav. 2005;86(1):92-95.

45. McCaffrey R, Thomas DJ, Kinelman AO. The effects of lavender and rosemary essential oils on test-taking anxiety among graduate nursing students. Holist Nurs Pract. 2009;23(2):88-93.

46. Chen YJ, Shih Y, Chang TM, Wang MF, Lan SS, Cheng FC. Inhalation of neroli essential oil and its anxiolytic effects in animals. In: Spink AJ, Ballintijn MR, Bogers ND, et al (editors). Proceedings of Measuring Behavior 2008: 6th International Conference on Methods and Techniques in Behavioral Research. Wageningen, the Netherlands: Noldus Information Technology; 2008:256-257.

47. Muzzarelli L, Force M, Sebold M. Aromatherapy and reducing preprocedural anxiety: a controlled prospective study. Gastroenterol Nurs. 2006;29(6):466-471.

48. Kritsidima M, Newton T, Asimakopoulou K. The effects of lavender scent on dental patient anxiety levels: a cluster randomised-controlled trial. Community Dent Oral Epidemiol. 2010;38(1):83-87.

49. Toda M, Morimoto K. Effect of lavender aroma on salivary endocrinological stress markers. Arch Oral Biol. 2010;53(10):964-968.

50. Shapiro M, Melmed RN, Sgan-Cohen HD, Eli I, Parush S. Behavioural and physiological effect of dental environment sensory adaptation on children's dental anxiety. Eur J Oral Sci. 2007;115(6):479-483.

51. Cermak SA, Stein Duker LI, Williams ME, et al. Feasibility of a sensory-adapted dental environment for children with autism. Am J Occup Ther. 2015;69(3):1-10.

52. Shapiro M, Melmed RN, Sgan-Cohen HD, Parush S. Effect of sensory adaptation on anxiety of children with developmental disabilities: a new approach. Pediatr Dent. 2009;31(3):222-228.

53. Marci CD, Ham J, Moran E, Orr SP. Physiologic correlates of perceived therapist empathy and social-emotional process during psychotherapy. J Nerv Ment Dis. 2007;195(2):103-111.

54. Friedman N. Iatrosedation: the treatment of fear in the dental patient. J Dent Educ. 1983;47(2):91-95.

55. Friedman N, Wood GJ. An evaluation of the iatrosedative process for treating dental fear. Compend Contin Educ Dent. 1998;19(4):434-436, $438,440-442$.

56. Botto RW. Chairside techniques for reducing dental fear. In: Mostofsky DI, Forgione AG, Giddon DB, editors. Behavioral Dentistry. Oxford: Blackwell; 2006:115-125.

57. Corah NL. Dental anxiety: assessment, reduction and increasing patient satisfaction. Dent Clin North Am. 1988;32(4):779-790.

58. Jacobson E. Progressive Relaxation. Chicago: University of Chicago Press; 1938.

59. Loew TH, Tritt K, Siegfried W, Bohmann H, Martus P, Hahn EG. Efficacy of "functional relaxation" in comparison to terbutaline and a "placebo relaxation" method in patients with acute asthma: a randomized, prospective, placebo-controlled, crossover experimental investigation. Psychother Psychosom. 2001;70(3):151-157.

60. Lahmann C, Nickel M, Schuster T, et al. Functional relaxation and guided imagery as complementary therapy in asthma: a randomized controlled clinical trial. Psychother Psychosom. 2009;78(4): 233-239. 
61. Pikoff H. A critical review of autogenic training in America. Clin Psychol Rev. 1984;4(6):619-639.

62. Ost LG. Applied relaxation: description of a coping technique and review of controlled studies. Behav Res Ther. 1987;25(5):397-409.

63. Biggs QM, Kelly KS, Toney JD. The effects of deep diaphragmatic breathing and focused attention on dental anxiety in a private practice setting. J Dent Hyg. 2002;77(2):105-113.

64. Benson H. Timeless Healing: The Power and Biology of Belief. New York: Scribner; 1996.

65. Benson H, Beary JF, Carol MP. The relaxation response. Psychiatry. 1974;37(1):37-46.

66. Tusek D, Church JM, Fazio VW. Guided imagery as a coping strategy for perioperative patients. AORN J. 1997;66(4):644-649.

67. Hofmann SG, Sawyer AT, Witt AA, Oh D. The effect of mindfulnessbased therapy on anxiety and depression: a meta-analytic review. J Consult Clin Psychol. 2010;78(2):169-183.

68. Gonzales EA, Ledesma RJ, McAllister DJ, Perry SM, Dyer CA, Maye JP. Effects of guided imagery on postoperative outcomes in patients undergoing same-day surgical procedures: a randomized, single-blind study. AANA J. 2010;78(3):181-188.

69. Hirschman R. Physiological feedback and stress reduction. Poster presented at: Annual Meeting of Society of Behavioral Medicine; November 1980; New York.

70. Milgrom P, Weinstein P, Heaton LJ. Treating Fearful Dental Patient: A Patient Management Handbook. 3rd ed. Seattle: University of Washington; 2009.

71. Agnihotri H, Paul M, Sandhu JS. Biofeedback approach in the treatment of generalized . Iran J Psychiatry. 2007;2(3):90-95.

72. Morarend QA, Spector ML, Dawson DV, Clark SH, Holmes DC. The use of a respiratory rate biofeedback device to reduce dental anxiety: an exploratory investigation. Appl Psychophysiol Biofeedback. 2011; 36(2):63-70.

73. Facco E, Zanette G, Casiglia E. The role of hypnotherapy in dentistry. SAAD Dig. 2014;30:3-6.

74. Montgomery GH, DuHamel KN, Redd WH. A meta-analysis of hypnotically induced analgesia: how effective is hypnosis? Int J Clin Exp Hypn. 2000;48(2):138-153.

75. Flammer E, Bongartz W. On the efficacy of hypnosis: a meta-analytic study. Contemp Hypn. 2003;20(4):179-197.

76. Glaesmer H, Geupel H, Haak R. A controlled trial on the effect of hypnosis on dental anxiety in tooth removal patients. Patient Educ Couns. 2015;98(9):1112-1115.

77. Ernst E, Pittler MH. The effectiveness of acupuncture in treating acute dental pain: a systemic review. Br Dent J. 1998;184(9):443-472.

78. Rosted $P$. The use of acupuncture in dentistry: a review of the scientific validity of published papers. Oral Dis. 1998;4(2):100-104.

79. Karst M, Winterhalter M, Münte S, et al. Auricular acupuncture for dental anxiety: a randomised controlled trial. Anesth Analg. 2007;104(2):295-300.

80. Ma R, Xu SJ, Wen XY, et al. Acupuncture for generalized anxiety disorder: a systematic review. J Psychol Psychother. 2014;4(5): 1000155.

81. Pilkington K, Kirkwood G, Rampes H, Cummings M, Richardson J. Acupuncture for anxiety and anxiety disorders - a systematic literature review. Acupunct Med. 2007;25(1-2):1-10.

82. Au DW, Tsang HW, Ling PP, Leung CH, Ip PK, Cheung WM. Effects of acupressure on anxiety: a systematic review and meta-analysis. Acupunct Med. 2015;33(5):353-359.

83. American Academy of Pediatric Dentistry. Special issue: Proceedings of the conference on behavior management for the pediatric dental patient. Pediatr Dent. 2004;26(2):110-183.

84. Ram D, Shapira J, Holan G, Magora F, Cohen S, Davidovich E. Audiovisual video eyeglass distraction during dental treatment in children. Quintessence Int. 2010;41(8):673-679.

85. White JM. State of the science of music interventions: critical care and perioperative practice. Crit Care Nurs Clin North Am. 2000; 12(2):219-225.
86. Moola S, Pearson A, Hagger C. Effectiveness of music interventions on dental anxiety in paediatric and adult patients: a systematic review. JBI Database System Rev Implement Rep. 2011;9(18):588-630.

87. Allen KD, Stanley RT, McPherson K. Evaluation of behavior management technology dissemination in pediatric dentistry. Pediatr Dent. 1990;12(2):79-82.

88. Farhat-McHayleh N, Harfouche A, Souaid P. Techniques for managing behaviour in pediatric dentistry: comparative study of live modelling and tell-show-do based on children's heart rates during treatment. J Can Dent Assoc. 2009;75(4):283.

89. Wolpe J. Reciprocal inhibition as the main basis of psychotherapeutic effects. AMA Arch Neurol Psychiatry. 1954;72(2):205-226.

90. Carter AE, Carter G, Boschen M, AlShwaimi E, George R. Pathways of fear and anxiety in dentistry: a review. World J Clin Cases. 2014;2(11):642-653.

91. Roberts JF, Curzon ME, Koch G, Martens LC. Review: behaviour management techniques in paediatric dentistry. Eur Arch Paediatr Dent. 2010;11(4):166-174.

92. Dumitrache MA, Neacsu V, Sfeatcu IR. Efficiency of cognitive technique in reducing dental anxiety. Procedia Soc Behav Sci. 2014;149:302-306.

93. Bray A, Chhun A, Donkersgoed R, Hoover S, Levitan S. An evidencebased report investigating the most effective method to reduce dental anxiety. 2009. Available from: https://www.dentistry.utoronto.ca/ system/files/x3eblreport-2009.pdf. Accessed November 28, 2015.

94. Heaton LJ. Behavioral interventions may reduce dental anxiety and increase acceptance of dental treatment in dentally fearful adults. J Evid Based Dent Pract. 2013;13(4):160-162.

95. Getka EJ, Glass CR. Behavioral and cognitive-behavioral approaches to the reduction of dental anxiety. Behav Ther. 1992;23(3): 433-448.

96. Bowman U, Carlsson V, Westin M, Hakeberg M. Psychological treatment of dental anxiety among adults: a systematic review. Wide. Eur J Oral Sci. 2013;121(3 Pt 2):225-234.

97. Berggren U, Hakeberg M, Carlsson SG. Relaxation vs. cognitively oriented therapies for dental fear. J Dent Res. 2000;79(9):1645-1651.

98. Heaton LJ, Leroux BG, Ruff PA, Coldwell SE. Computerized dental injection fear treatment: a randomized clinical trial. J Dent Res. 2013;92(7 Suppl):S37-S42.

99. Fukayama H, Yoshikawa F, Kohase H, Umino M, Suzuki N. Efficacy of anterior and middle superior alveolar (AMSA) anesthesia using a new injection system: the Wand. Quintess Int. 2003;34(7):537-541.

100. Zhao X, Liu H, Qin M. [Application of computer-controlled local anesthetic delivery system in children]. Hua Xi Kou Qiang Yi Xue Za Zhi. 2011;29(4):389-392. Chinese.

101. Yap AU, Henry CW. Electronic and local anesthesia: a clinical comparison for operative procedures. Quintessence Int. 1996;27(5): 549-553.

102. Dhindsa A, Pandit IK, Srivastava N, Gugnani N. Comparative evaluation of the effectiveness of electronic dental anesthesia with $2 \%$ lignocaine in various minor pediatric dental procedures: a clinical study. Contemp Clin Dent. 2011;2(1):27-30.

103. Jacobs $R$, van Steenberghe D. The effect of electronic dental analgesia during sonic scaling. J Clin Periodontol. 1994;21(10):728-730.

104. Coldwell SE, Getz T, Milgrom P, Prall CW, Spadafora A, Ramsay DS. CARL: a LabVIEW 3 computer program for conducting exposure therapy for the treatment of dental injection fear. Behav Res Ther. 1998;36(4):429-441.

105. Patel MX, Baker D, Nosarti C. Injection phobia: a systematic review of psychological treatments. Behav Cogn Psychother. 2005; 33(3):343-349.

106. Reddy RS, Kotha R, Pavani K, Subbarayudu G, Rajesh N, Sruthi R. Dental anxiety - neglect of dental care. International Journal of Health. 2015;3(1):20-23.

107. Folayan MO, Faponle A, Lamikanra A. Seminars on controversial issues. A review of the pharmacological approach to the management of dental anxiety in children. Int J Paediatr Dent. 2002; 12(5):347-354. 
108. Newton T, Asimakopoulou K, Daly B, Scambler S, Scott S. The management of dental anxiety: time for a sense of proportion? Br Dent J. 2012;213(6):271-274.

109. Coulthard P. The indicator of sedation need (IOSN). Dent Update. 2013;40(6):466-468, 470-471.

110. Intercollegiate Advisory Committee for Sedation in Dentistry. Standards for Conscious Sedation in the Provision of Dental Care. London: RCS Publications; 2015. Available from: https://www. rcseng.ac.uk/fds/Documents/dental-sedation-report-2015-web-v2. pdf. Accessed November 29, 2015.

111. British Dental Association. Conscious Sedation. London: BDA; 2011. Available from: http://www.baos.org.uk/resources/ BDAGuidanceconscious_sedation_-_nov_11.pdf. Accessed November 29, 2015.

112. O'Halloran M. The use of anaesthetic agents to provide anxiolysis and sedation in dentistry and oral surgery. Australas Med J. 2013;6(12):713-718.

113. Levering NJ, Welie JV. Current status of nitrous oxide as a behavior management practice routine in pediatric dentistry. J Dent Child (Chic). 2011;78(1):24-30.

114. Berggren U. Long-term management of the fearful adult patient using behavior modification and other modalities. J Dent Educ. 2001;65(12):1357-1368.

115. Willumsen T, Vassend O. Effects of cognitive therapy, applied relaxation and nitrous oxide sedation: a five-year follow-up study of patients treated for dental fear. Acta Odontol Scand. 2003;61(2):93-99.
116. Thom A, Sartory G, Jöhren P, Deecke L. Comparison between onesession psychological treatment and benzodiazepine in dental phobia. J Consult Clin Psychol. 2000;68(3):378-387.

117. Jaafer NA, Izadi M, Daly B, Newton JT. The social validation of pharmacological approaches to the management of dental anxiety in adults: impact of treatment urgency, method of intervention and treatment outcome. Soc Behav Pers. 2007;35(3):375-386.

118. Kvale G, Berggren U, Milgrom P. Dental fear in adults: a metaanalysis of behavioral interventions. Community Dent Oral Epidemiol. 2004;32(4):250-264.

119. Forbes MD, Boyle CA, Newton T. Acceptability of behaviour therapy for dental phobia. Community Dent Oral Epidemiol. 2012; 40(1):1-7.

120. Newton JT, Naidu R, Sturmey P. The acceptability of the use of sedation in the management of dental anxiety in children: views of dental students. Eur J Dent Educ. 2003;7(2):72-76.

121. Jacobson's progressive relaxation technique (leaflet 2926/VER2). Guy's and St Thomas' NHS Foundation Trust. Date published: January 2016; Review date: January 2019. Available from http:// www.guysandstthomas.nhs.uk/resources/patient-information/ cardiovascular/jacobsons-progressive-relaxation-technique.pdf.
Clinical, Cosmetic and Investigational Dentistry

\section{Publish your work in this journal}

Clinical, Cosmetic and Investigational Dentistry is an international, peer-reviewed, open access, online journal focusing on the latest clinical and experimental research in dentistry with specific emphasis on cosmetic interventions. Innovative developments in dental materials, techniques and devices that improve outcomes and patient satisfac-

\section{Dovepress}

tion and preference will be highlighted. The manuscript management system is completely online and includes a very quick and fair peerreview system, which is all easy to use. Visit http://www.dovepress. com/testimonials.php to read real quotes from published authors. 